\title{
The 'Degree of Inclusion' in Inclusive Education, Prerogative of Schools and Difficulties of Special Needs Educators
}

\author{
Shagnik Saha \\ ${ }^{1}$ Assistant Professor, Department of Psychology, Amity University, Mumbai. \\ Corresponding author: Shagnik Saha \\ Email - shagniksaha.ss@gmail.com
}

\begin{abstract}
This article explores the current difficulties in the Special Needs field from the perspectives of various stakeholders such as the schools, the Special Educators, the Special Needs students as well as the popular opinions and views about research and attempts to graphically represent the scenario for better understanding. Large-scale disconnect between the actual receivers of Special Education-efforts, the Special Educators and the bureaucracy and media who are largely running after a fad without paying heed to actual in-field realizations and understandings, which in turn is causing more harm than good is being seen. Special Needs Educators are being pressurized to give results in instances where it is quite difficult to get those results and in cases of failure, the blame is put on their capabilities.
\end{abstract}

Keywords: Special education, Inclusive education, Inclusion, Limitations of inclusion.

(Paper received $-29^{\text {th }}$ December 2017, Peer review completed $-3^{\text {rd }}$ January 2018)

(Accepted $-6^{\text {th }}$ January 2018)

\section{INTRODUCTION}

Inclusion is now widely concerned to be the future of education and it seems all the more natural when it is put in context with what it actually means. According to Salend, Inclusion is the structure by virtue of which individuals have the means to gain education with their peers without any distinction based on the lines of castes, genders, racial heritages, sex, sexual orientations, financial and economic means, ethnic background, or culture. One must realize that this is indeed a model that truly captures the global environment and discourse on not only human management, but also the revision of societal constructs of appropriateness and acceptability. It can now practically be seen what societal value is and the various mechanisms through which societies through the ages have consistently identified groups of individuals with lesser value and then allocated lesser opportunities to them [1].

With only a semi-permeable glance towards the global stage one is able to find significant proof of this, not only in terms of laws or regulations but also in terms of popular burgeoning ideation amongst laymen and professionals alike, supported by the understanding that what is deviant is only relative to the individual measuring it [2]. This environment of growing popularity of Inclusion that started in 1959 due to the efforts of Bank-Mikkelsen and Nirje, finally reached the first formal culmination in the form of the Salamanca Statement and Framework for Action on Special Needs Education that outlined and delineated exhaustive changes to the very foundations of the educational system to endure the inclusivity of individuals with special needs. 
India ratified the Salamanca Statement, and this growing movement found further steam by virtue of the UN Convention on the Rights on the Rights of Persons with Disabilities (UNCRPD), ratified by India in September 2007, finally coming into force on May, 2008. As far as the Indian scenario is concerned, the first impetus for that was the decision by the Kothari Commission (1966), followed by the Integrated Education for Disabled Children (IEDC, 1974), the National Policy on Education (1986), The Rehabilitation Council of India Act (1992), The Person with Disability Act (1995), the National Trust for Welfare of Persons with Autism, Cerebral Palsy, Mental Retardation and Multiple Disabilities Act (1999), Sarva Siksha Abhiyan (2002), the National Policy for Persons with Disability (2006), and more recently the Right of Children for Free and Compulsory Education (2009). Along with all of these Acts, Laws and Regulations and also because of this there has been increasing pressure on schools by Education Boards such as CBSE, ISCE, and IB to turn inclusive.

One must also understand that a school apart from being an institution of growth, is also in today's date an entrepreneurship, especially in the Private setting and therefore it is only expected that it also focusses on its image and therefore wouldn't want to be seen in an unfavorable light. This leads schools to abruptly turn inclusive without having the infrastructural or technical know-how to support the aforementioned model of inclusive education [1]. It might be quite easy to point fingers at schools and call them the bad guys but then at the same time it is imperative that we pay attention to their prerogative as well. Taking the business model of a school, we can say that it functions on the presence of an adequate number of students who are required to fund the basic financial requirements of the school in terms of salaries, rents, bills, endless stationery and so on and so forth. Needless to say, schools work in the sweet spot of having enough students for the advancement of the entrepreneurial aspect of the school but at the same time, ideally, not compromising on the quality of academic dissemination and character building responsibilities that schools are bestowed with. Factors such as lack of good academicians, or the absence of adequate liquid funds send a flying stump into the tracks of schools. For instance, even factors like absence of power generators, that wouldn't have mattered much earlier, are becoming a major concern these days as more and more schools are utilizing electronic media such as PowerPoint presentations, audio-visual clips, etc., not only as one-off impetuses but as consistent methods of information dissemination and concept clarification.

The days of pen and paper education are quickly receding to the margins of the society. In these scenarios, it becomes all the more important for schools to start accumulating resources just to keep the institution running and functional. One of the ways that this cost-cutting is done, is by getting academicians with lower teaching capabilities. Apart from the obvious reduction in educational expertise of the school as a whole, teachers who perceive themselves as ineffectual more often tend to consider inclusive education as inappropriate and refer students out [2]. One of the other ways is to take in Special Needs students and use the status of being an Inclusive School as a badge for higher status and as a symbol of higher caliber of the faculty. It is also used to show the higher moral values that the institution is based on and which would consequently be inculcated into the students who take admission there. Parents are usually taken around the school and the students with Disabilities are pointed out to establish the efficacy and the value structure of the school and its Management [1]. One can easily see how this would go completely against the aim of Inclusive Education, but at the same time it is important that we take heed of the circumstances in which such a decision was made. Said decision was not made, to purposefully hurt a particular child by intentionally making resources unavailable for him/her, however it was a cumulation of requirements and absences that finally led to this situation.

One of these absences is the shortage of Special Needs Educators, which has led to a lot of pressure on educational institutions [3]. Thus, we can see that even if schools were trying to hire capable special educators, it would be quite difficult to do even that. Interestingly, the flip side of this is that this current shortage of Special Educators is not because lesser and lesser people are entering the field, the shortage is actually happening because more and more people are leaving it because of the dissatisfaction with the support from the rest of the departments and the unavailability of the basic resources that are needed for proper functioning and deliverability of results [4]. Special Needs Educators are bogged down with way more students that they can handle, on top of that no assistance is provided whether in terms of manpower 
or resources and finally results are expected in a condition where ideally the child shouldn't be there in the first place, with the final lack of results being blamed on the lack of ability of the Special Educators $[5,1]$. Literature also shows that special educators who have more positive attitudes about Inclusive education, experience more burnout because they are the ones who come into the field with higher expectations and a desire to deliver better results which when stumped lead to a wider and deeper state of distraught [5].

One of the reasons that this dissatisfaction is happening is because of the inability of the institution or the media to understand and focus on what is called the Degree of Inclusion, which is basically the extent of severity till which individuals can be accepted into an inclusive educational system [1]. One can say that is quite a taboo and controversial topic, simply because it goes against the grain of complete inclusivity and with the hypersensitive culture that has been brought about in the current day and age, even a discussion about such topics would be considered basal and perhaps unethical.

However, the fact remains that not all individuals with Mental Disorder/ Disability can be put into an inclusive school because it would be very difficult for students with varying conditions to keep up with the traditional requirements that invariably creep in to the current inclusive education setting [6]. For instance, it would be practically impossible for a student with Severe Intellectual Disability to engage effectively in an environment with such a multitude of stimuli in terms of type of interactions, number of interactions, information being disseminated, appropriateness of responses and so on. Similarly, someone with Severe Autism needs the one-to-one engagement, lack of social distraction and intense social skills training that is not possible long-term or effectively, while depending singularly on an inclusive school [7-8]. In fact this has been evidenced in literature as well, wherein a study was done by Avramidis and Norwich where they observed the absence of a 'zero-reject' policy with the clear evidence of perceptions being drawn from child-condition-severity variables. Even emotionally for the child as well, there have been endless reports of students on the Autistic Spectrum who have been put into inclusive schools, coming out with lower levels of self-worth and social reciprocity and companionship [9-10].

\section{CONCLUSION}

Therefore, we can see the large-scale disconnect between the actual receivers of Special Education-efforts, the Special Educators and the bureaucracy and media who are largely running after a fad without paying heed to actual in-field realizations and understandings, which in turn is causing more harm than good. Special Needs Educators are being pressurized to give results in instances where it is quite difficult to get those results and in cases of failure, the blame is put on their capabilities. Finally, not being able to get the support from those higher up in the hierarchy, and at the same time not being able to help Special Needs students, Special Educators are leaving the field, only to increase the shortage and increase the pressure on those that remain, therefore one can see the vicious cycle that is currently in place with the only actual result being that the Special Needs students are the ones who are becoming the actual victims in this ironic condition where this entire exercise to help them, is what is harming them.

\section{REFERENCES}

1. Saha S. Difficulties and Exploitation in Inclusive Schooling: In-Field Reflections in Mental Disorder/ Disability Inclusion in India. J Psychosoc Res 2007;12(2):295-303.

2. Podell DM, Soodak LC. Teacher efficacy and bias in special education referrals. J Education Res 1993;86(4):247-53.

3. Thornton B, Peltier G, Medina R. Reducing the special education teacher shortage. The Clearing House: A Journal of Educational Strategies, Issues and Ideas 2007;80(5):233-8.

4. Brownell MT, Smith SW, McNellis JR, Miller MD. Attrition in special education: Why teachers leave the classroom and where they go. Exceptionality 1997;7(3):143-55.

5. Talmor R, Reiter S, Feigin N. Factors relating to regular education teacher burnout in inclusive education. Eur J Special Needs Educ 2005;20(2):215-29.

6. Teacher TS. Secret teacher: I am all for inclusion in principle, but it doesn't always work. [Internet] [2015, May 23] Accessed from https://www.theguardian.com/teacher-network/ 2015/may/23/secret-teachersupport-inclusion-but-not-at-any-cost 
7. Irmsher K. Inclusive Education in Practice: The Lessons of Pioneering School Districts. OSSC Bulletin 1995;38(6):n6.

8. McCarty K. Full Inclusion: The Benefits and Disadvantages of Inclusive Schooling. An Overview. Online Submission ; 2006.

9. Chamberlain B, Kasari C, Rotheram-Fuller E. Involvement or isolation? The social networks of children with autism in regular classrooms. J Autism Dev Disord 2007;37(2):230-42.

10. Gersten R, Keating T, Yovanoff $\mathrm{P}$, Harniss MK. Working in special education: Factors that enhance special educators' intent to stay. Exceptional Child 2001;67(4):549-67.

$* * * * * * * * * * * * * * * * * * * * * *$

Acknowledgements - Nil

Conflict of Interest - Nil

Funding - Nil

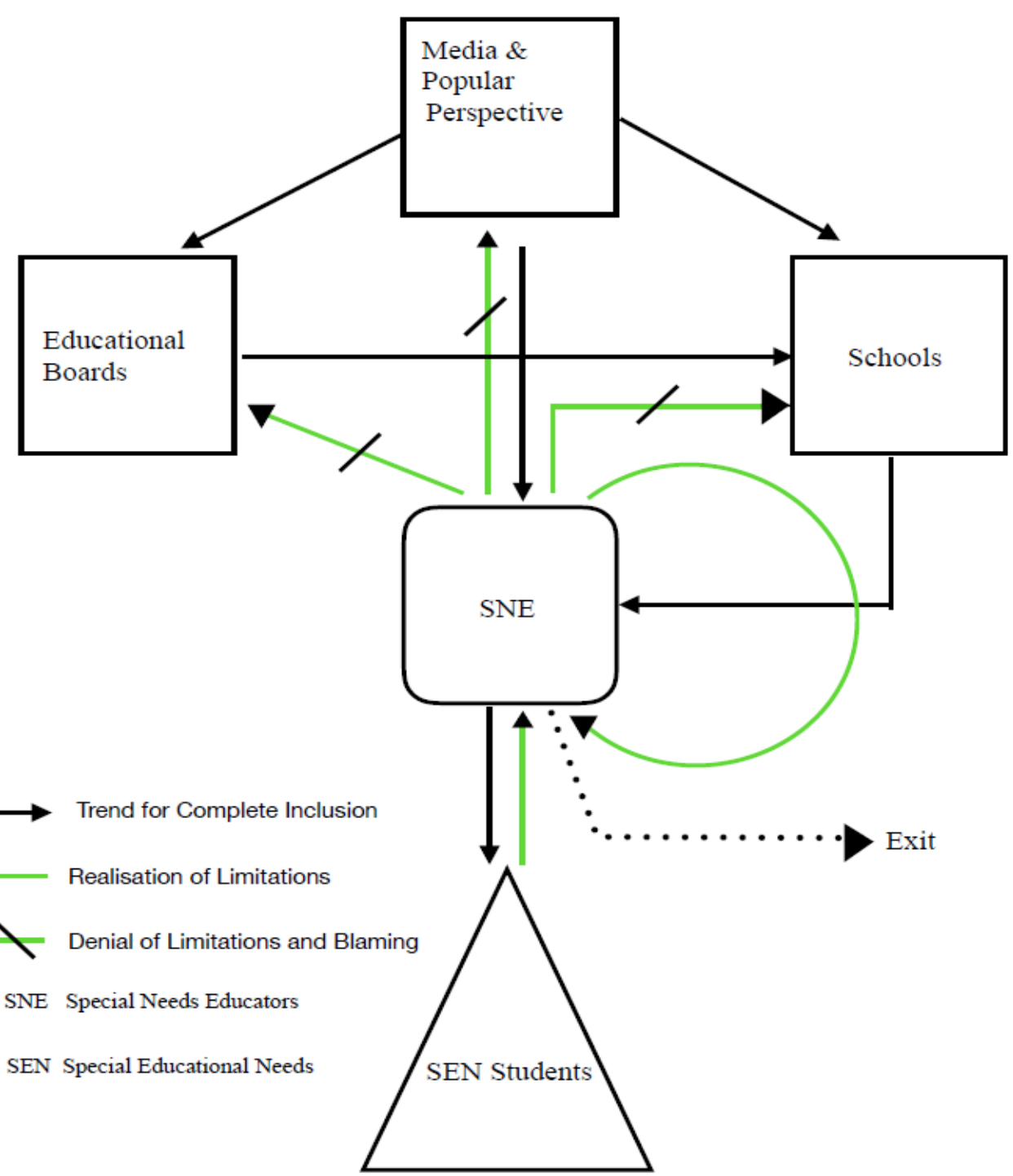

